\title{
Multi-scenario Active Distribution Network Planning Considering of Demand Response and Emission Reduction
}

\author{
Nan Li
}

\begin{abstract}
Active distribution network promotes the power systems rely less on large-scale power plants and transmission networks, which brings new challenges to the distribution network planning. This paper sets up an active distribution network planning model based on integration of operation and planning, studies a new active distribution network operation mode containing demand side response, and puts forward temporary additional price incentives to promote renewable distributed generation (RDG) absorption. In view of the uncertainty of RDG, Multi-scenario probability model is used to simulate the actual output of RDG. This paper sets up an active distribution network planning model with the optimization target of minimum of construction operation cost, renewable energy output cutting quantity and carbon emission, and the constraints contain users' satisfaction about electricity supply and reduction of loads. Simulation of IEEE33 nodes distribution system show that the model can effectively solve high permeability of DG, give full play to the advantage of the demand response for distribution network, and achieve rational economic and environmental planning solutions. The adopted algorithm can effectively deal with different objective functions with different dimension.
\end{abstract}

Index Terms-Active distribution network, renewable distributed generation, demand response, emission reduction.

\section{INTRODUCTION}

Energy crisis and environmental deterioration are issues that need urgent solving [1], and distributed generation (DG) mainly based on the renewable energy is considered as an important generation way of electrical energy for its features of high efficiency, environmental protection and energy saving. However, the improvement of penetration rate of DG and its grid-connected operation will influence greatly on traditional distribution network in the operation mode, management mode and control mode. The large-scale application of DG will evolve the passive, single-direction and single-power distribution network to become active, multi-direction and multi-power distribution system, which is to become Active Distribution Network (ADN) [2]. C6.11 working team of International Council on Large Electric Systems (CIGRE) put forward the concept of active distribution network in 2008 [3] which clearly shows that ADN can alter power flow via flexible network topology so that active control and active management can be done to

Manuscript received October 15, 2015; revised February 10, 2016.

$\mathrm{Nan} \mathrm{Li} \mathrm{is} \mathrm{with} \mathrm{the} \mathrm{State} \mathrm{Grid} \mathrm{Energy} \mathrm{Research} \mathrm{Institute,} \mathrm{Beijing,} \mathrm{China}$ (e-mail: linanyz@163.com). local distributed energy.

Access of lots of DG poses challenges to the distribution network planning. The traditional distribution network planning methods adopt maximum capacity margin (setting a fixed network structure) according to some predicted values of load, to deal with the most serious working condition [4]-[6]. These methods can find the optimal solution to solve all operation issues on the stage of planning, so traditional planning is much easier. ADN planning is much more complex, all kinds of operation conditions should be considered on the stage of planning. With the improvement of penetration rate of $\mathrm{DG}, \mathrm{ADN}$ planning should consider coordination optimization issues of all power supplies, including coordination with the transmission grid.

Nowadays, domestic and foreign scholars have conducted a series of research on ADN planning. References [7], [8] summarized difference between $\mathrm{ADN}$ and passive distribution network planning, and put forward issues facing the ADN planning. Reference [9] put forward Key issues and the future major research orientation in the field of ADN planning from five aspects including load forecasting, resources features, integrated design modes, optimized methods and cost-benefit analysis. References [10]-[12] put forward dynamic planning model of ADN, and many aspects of indicators were integrated in the objective function. But these literatures involve less on operation features of ADN, random volatility of renewable distributed generation (RDG) and flexibility of network topology changing is flexible.

This paper researches the operation ways of ADN taking into account demand response, builds a ADN planning model based on the integration of planning and operation, adopts multi-scenario probability method to simulate the output of RDG and temporary additional electricity price to facilitate its absorption, proposes users' satisfaction about electricity supply to be the evaluation indicator of demand response. The ADN planning objectives are low cost construction and operation, high utilization efficiency of RDG and emission reduction. Non-dominated sorting genetic algorithm II (NSGA-II [13]) is introduced to the field of distribution network planning to meet the need of coordination optimization of multi-dimensional objectives and to overcome the impact of weight on optimization results in the traditional optimization algorithms. The simulating results of IEEE33 distribution system show that this model considers operation features of DG, covers the interaction between power sources and users and gives full play to the positive impact of demand response on distribution network planning, which have a high value of practical application. 


\section{DEMAND RESPONSE INCLUDING RDG}

Electricity Demand Response (DR) is a market participation behavior that users respond to signal of electricity prices or incentive mechanism and then change the habits of normal electricity consumption [14]. There are mainly two responding forms [15], single-period respond and multi-period respond. The single-period respond means that users' power consumption within a certain period is only related to the temporal electricity price. The multi-period respond means that users' power consumption within a certain period is not only related to the temporal electricity price, but also to electricity prices of other periods. This implies users not just simply decrease their temporal power consumption but transfer the load from high electricity prices periods to the low prices period. In fact, the power consumption of most users during a certain period not only relates to the electricity price of temporal period, but also is influenced by the electricity price of the adjacent periods.

The single-period respond and multi-period respond of power consumption to electricity prices are as in

$$
\begin{gathered}
d(i)=d_{0}(i) \times\left\{1+\frac{\varepsilon_{i i} \times\left[\rho(i)-\rho_{0}(i)\right]}{\rho_{0}(i)}\right\} \\
d(i)=d_{0}(i)+\sum \varepsilon_{i j} \times \frac{d_{0}(i)}{\rho_{0}(j)} \times\left[\rho(j)-\rho_{0}(j)\right]
\end{gathered}
$$

where, $\rho_{0}$ and $\rho$ are primary electricity prices and time-of-use electricity prices respectively; $d_{0}$ and $d$ are power demands of users before and after the time-of-use electricity prices respectively; $\varepsilon_{i i}$ is self-elasticity coefficient; $\varepsilon_{i j}$ is cross-elasticity coefficient; $i$ and $j$ are different periods.

\section{A. Temporary Additional Electricity Price to Solve Output Fluctuation of RDG}

Traditional DR model formulates peak-usual-valley TOU electricity prices according to daily load curve. The electric price increases during high load periods to decrease the load and decreases during the period of valley to encourage power consumption in order to decrease the maximum load and difference between peak and valley load. Power transmission from the superior grid to the distribution company is generally ahead-of-time dispatch. When the actual output of RDG exceed much than predicted output, power balance can only be achieved via RDG output reduction. Fig. 1 draws a curve of actual output of RDG on the basis of RDG predicted output In the traditional mode, when the actual output of RDG exceeds predicted output, the exceeding part will be directly decreased; when the actual output of RDG is lower than the predicted output, the absent output will be compensated by reserve units. Such ways will decrease the utilization efficiency of RDG and increase the operation costs, which are unbeneficial to reasonable allocation of resources.

On the basis of time-of-use electricity price during peak-usual-valley periods, this paper put forward an electricity price adjustment method, temporary additional electric price, additional price for short, in order to solve the random fluctuation of RDG output. When RDG output is deviation from the predicted output, additional price will be added to TOU price. When RDG output exceeds the predicted output, the additional price is negative to encourage users to increase power consumption so that surplus output of RDG can be consumed, wind and light curtailment can be reduced. On the contrary, additional price is positive to encourage users to reduce power consumption and relieve the pressure of reserve units, As in Fig. 1. Temporary additional electricity price can be formulated in section according to the numerical values that RDG diverging the predicted output. Under the serious circumstances, the electricity price may fluctuate in real-time. As the advanced stage of smart grid, ADN carries the dual-direction flows of information and energy and should pass electricity price information to users in real-time.

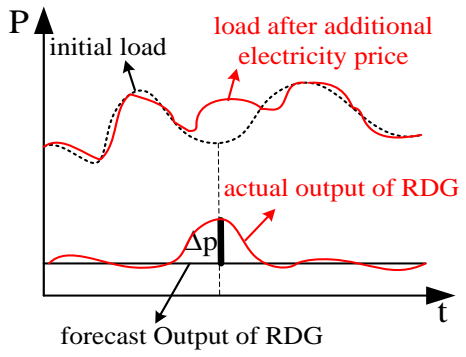

Fig. 1. The influence of additional electricity for load.

\section{B. Indicator of Users' Satisfaction about Electricity Supply}

To encourage users to participate in DR actively and to lower the maximum load so that investment of fixed equipment of distribution network can be decreased, users' satisfaction degree on electricity price strategy and electricity consumption should be taken into full consideration. This paper takes users' satisfaction about electricity supply as a measure indicator.

Suppose that before the implementation of DR, the electricity sale price of distribution company is $\rho_{0}$, users' daily power consumption is $Q_{0}$. After the implementation of DR, TOU prices are $\rho_{f}, \rho_{p}$ and $\rho_{g}$ respectively, and power consumption during the peak, usual and valley periods are $Q_{f}$, $Q_{p}$, and $Q_{g}$ respectively. Therefore, daily electricity charges for users before and after DR are as in

$$
\begin{gathered}
C M_{0}=\rho_{0} Q_{0} \\
C M=\rho_{f} Q_{f}+\rho_{p} Q_{p}+\rho_{g} Q_{g}
\end{gathered}
$$

Obviously, after the implementation of DR, users' satisfaction about electricity supply can be higher if they spend fewer fees on purchasing more electricity. The quantization expression of users' satisfaction is as in (5). This expression can be interpreted as that the less spending of unit electricity, the higher satisfaction degree for users.

$$
S=\frac{Q_{f}+Q_{p}+Q_{g}}{Q_{0}} \times \frac{C M_{0}}{C M}
$$

\section{MUlTI-SCENARIO ADN PLANNING}

\section{A. ADN Planning Framework}

Electricity load and control modes of ADN are various and access points of DG are scattered and weak in control. Thus, 
ADN planning should integrate all "source" and "load" within the network together to fully show the core principle of ADN. We need to overcome technical difficulties of planning, fully consider network scale and complex structure of ADN, encourage users to actively participate in DR and power control of DG to decrease the peak and increase the off-peak as well as energy conservation and emissions reduction, improve the utilization efficiency of DG, achieve the high efficient economic control of ADN and develop ADN planning technique integration of planning and operation [16].

According to the above analysis, the obvious differences between ADN planning and traditional planning are active absorption ability of distribution network on DG, demand response of users and coordinated management of "source", "network" and "load". ADN planning framework shows as the Fig. 2.

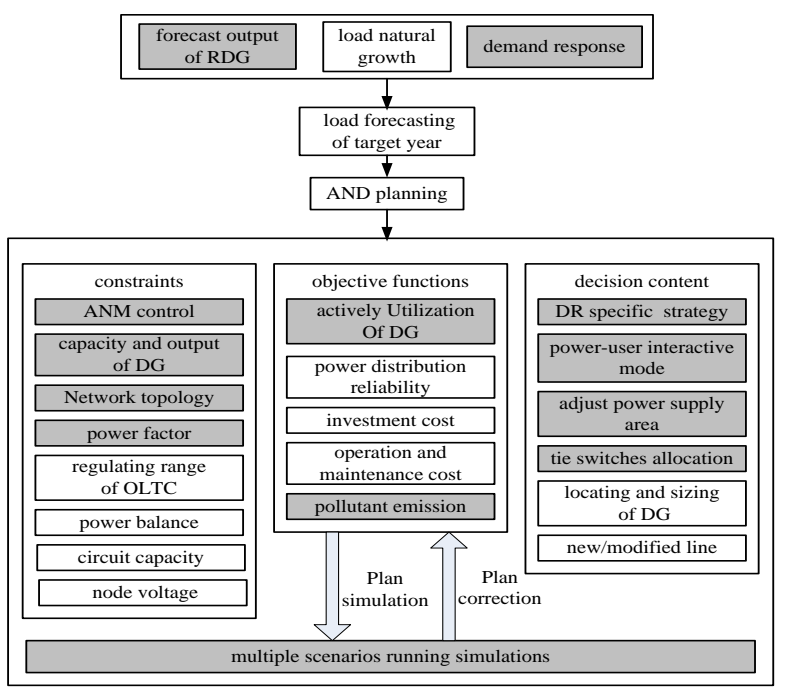

Fig. 2. Planning framework of active distribution network.

\section{B. Multi-scene Operation Ways in ADN Planning}

In $\mathrm{ADN}$, large scale access of renewable energy efficiency gives rise to issues of energy utilization. Constrained by the maximum power of purchased electricity from the superior grid, distribution network may face reduction of load or DG output. ADN operation should lower the reduction, which is to relieve phenomenon of discarding wind and light as well as reducing load reduction as soon as possible.

Reasonable operation ways of ADN is researched in this sector and operation way is divided into two steps: the first step is day-ahead dispatch, and the second step is intra-day rolling. In the first step, day-ahead optimization dispatch of transmission power from the superior grid to distribution network is completed according to prediction of RDG output, and output of reserve units in distribution network can be arranged. In the second step, real-time dispatch is completed according to RDG actual output, including adjusting output of reserve units, formulate temporary additional electricity prices, flexibly adjust load and so on.

According to RDG predicted output curve, we can set out several scenarios sections, as in Fig. 3. Generally, the actual output will fluctuate around predicted output and may be in different sections during different periods. Herein, define $u(t)$ as the output deviation of RDG at period $t$, and its expression is as in

$$
u(t)=\frac{P_{R D G}(t)-P_{R D G}^{r e f}(t)}{S_{R D G}}
$$

where, $P_{R D G}(t)$ is the actual output of RDG produced according to the probability, $P_{R D G}^{r e f}(t)$ is predicted output of RDG produced at period $t$ under typical condition, $S_{R D G}$ is installed capacity of RDG. Statistics of probability of actual output in all scenarios should be included, and temporary additional electricity price of all scenarios should be formulated in the intra-day operation. After users' respond to price changing, adjustment of reserve units output and reduction of RDG and load in all scenes should be calculated. Then, operation process of distribution network and users' satisfaction about electricity supply should be calculated on the basis of probability of different scenarios.

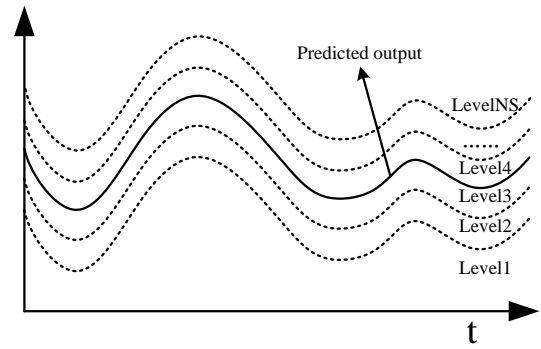

Fig. 3. Scenarios classification method.

\section{Planning Model of ADN}

Load of ADN will be influenced by DR and DG output. And the operation modes are not restricted to the original area of electricity supply because of flexible, adjustable and controllable grid structure of ADN. Three optimization objectives are considered in this sector: the first one is economic objective including investment and operation costs of distribution network; the second one is efficiency of DG utilization; the last one is emission reduction.

\section{1) Economic objective}

This indicator consists of the following two parts: the first is related with equipment investment and the second with equipment operation, as in

$$
\mathrm{TC}=\mathrm{TCI}+\mathrm{TOC}
$$

where, TIC is net present value of system investment costs and related with planning decision; TOC is net present value of predicted variable cost in the condition of all operations of system.

$$
\begin{aligned}
\mathrm{TIC}= & \sum_{\lambda=1}^{T Y} \frac{1}{(1+d)^{\lambda}}\left[\sum_{(i, j) \in \Omega_{F}} C_{a}^{f d r} l_{i j} \tau_{i j, \lambda}+\sum_{g \in \Omega_{G}^{g t}} C^{g t} n_{\lambda}^{g t}+\sum_{g \in \Omega_{G}^{w}} C^{w} n_{\lambda}^{w}+\sum_{g \in \Omega_{G}^{p v}} C^{p v} n_{\lambda}^{p v}\right] \\
& -\frac{1}{(1+d)^{T Y}}\left(\sum_{(i, j) \in \Omega_{F}} Z_{a}^{f d r}+\sum_{g \in \Omega_{G}^{g t}} Z^{g t}+\sum_{g \in \Omega_{G}^{w}} Z^{w}+\sum_{g \in \Omega_{G}^{p v}} Z^{p v}\right)
\end{aligned}
$$


The first line of (8) means investment cost of feeders, gas turbines, wind generations and photovoltaic power stations in ADN. The second line means surplus value of all equipment when the planning periods end. $T Y$ is general planning years; $\Omega_{F}, \Omega_{G}^{g t}, \Omega_{G}^{w}$ and $\Omega_{G}^{p v}$ are sets of feeders and all types of DG; $C_{a}^{f d r}, C^{g t}, C^{w}$ and $C^{p v}$ are unit construction cost of feeders and all types of DG; $l_{i j}$ is length of the feeder; $\tau$ is a selected variable and $\tau=1$ means the specific feeders or DG is chose to be constructed; $n_{\lambda}^{g t}, n_{\lambda}^{w}$ and $n_{\lambda}^{p v}$ are installation numbers of gas turbines, wind generations and photovoltaic power stations in the year $\lambda$ respectively and $d$ is the rate of depreciation. Adopting the form of net present value means scope of planning periods should comply with lifetime of candidate equipment. To adapt this requirement, surplus value $Z$ of the equipment is considered, as in

$$
Z=\frac{C}{T L}[T L-(T Y-\lambda+1)]
$$

where, $Z$ means surplus value of the equipment after the end of planning periods, $C$ is basic construction cost; $T L$ is lifetime and $\lambda$ is investment years of this equipment. Surplus value should be reduced in the total investment during planning periods. By this way, equipment of different lifetime and different invested year during planning periods may be considered together.

As for the second part TOC, load after DR may be first calculated via (1) and (2), and then system operation fees, including electricity purchase fees from superior grid and operation cost of gas turbines will be acquired by calculation of power flow under every operation condition of the system.

$\mathrm{TOC}=\sum_{\lambda=1}^{T Y} \frac{1}{(1+d)^{\lambda}} \sum_{s=1}^{N S} P R_{s} \times \sum_{t=1}^{T H}\left\{\rho_{\lambda}^{g s p}(t) P_{s}^{g s p}(t)+\rho^{g t} \sum_{g \in \Omega_{G}^{g t}} P_{g, s}^{g t}(t)\right\}(10)$

where, $N S$ is number of scenarios; $T H$ is the general planning years; $P R_{s}$ is the probability of the $s$-th scenario; $\rho_{\lambda}^{g s p}$ is unit cost of purchasing electricity from the superior gird; $\rho^{g t}$ is unit generating cost of gas turbines; $P_{s}^{g s p}$ is purchasing electricity by distribution network from the superior gird; $P_{g, s}^{g t}$ is output of gas turbines.

\section{2) Objective of $D G$ utilization efficiency}

In the operation progress of ADN, when the output of RDG is quite large and users cannot consume it, output of RDG will be faced with reduction. In this paper, annual output reduction of unit capacity RDG is indicated for the utilization efficiency of RDG. The lower annual output is cut, the higher utilization efficiency RDG has.

\section{3) Objective of emission reduction}

Assuming $\mathrm{CO}_{2}$ is the main emission, the total volume of $\mathrm{CO}_{2}$ emission in the distribution network system during the planning periods is as in

$$
E_{\mathrm{CO}_{2}}=\sum_{\lambda=1}^{T Y} \sum_{s=1}^{N S} P R_{s} \times \sum_{t=1}^{T H}\left\{e_{C O_{2}}^{g s p} P_{s}^{g s p}(t)+e_{\mathrm{CO}_{2}}^{g t} \sum_{g \in \Omega_{G}^{g t}} P_{g, s}^{g t}(t)\right\}
$$

where, $e_{\mathrm{CO}_{2}}^{g s p}$ and $e_{\mathrm{CO}_{2}}^{g t}$ are $\mathrm{CO}_{2}$ emission volumes of coal-fired generations and gas turbine generations respectively $(\mathrm{g} / \mathrm{kWh})$. According to [17], $e_{\mathrm{CO}_{2}}^{g s p}$ is 822.802 $\mathrm{g} / \mathrm{kWh}$ and $e_{\mathrm{CO}_{2}}^{g t}$ is $402 \mathrm{~g} / \mathrm{kWh}$.

The following constrains should be considered in the process of planning:

a) Voltage constrain ( $N_{B}$ is number of nodes);

$$
V_{\min } \leq V_{i} \leq V_{\max }\left(i \in N_{B}\right)
$$

b) Constrain of users' satisfaction about electricity supply;

$$
S \geq S_{\min }
$$

c) Load shedding constrain:

In the multi-scenario operation process, ADN should adjust load reasonably, take advantage of reserve units and avoid load shedding as much as possible:

$$
\sum_{s=1}^{N S} P R_{s} \times L_{c u t}^{s}=0
$$

where, $L_{c u t}^{s}$ is the volume of load shedding in the $s$-th scenario.

d) Electricity sale prices should be within the reasonable scope.

$$
\rho_{\min } \leq \rho_{t} \leq \rho_{\max }(t \in T H)
$$

e) Constrained purchasing electricity by distribution network from the superior grid.

$$
P_{g s p}(t) \leq P_{g s p}^{\max }(t \in T H)
$$

f) Constrained of network topology structure

- In the operation, two substations should not be connected directly via lines;

- Nodes of every substation and loads supplied by it should be integrated into a radial network;

- Circuits consist of load nodes alone should be avoided, that is every load node should be connected with a substation node.

\section{ANALYSIS OF ALGORITHM EXAMPLES}

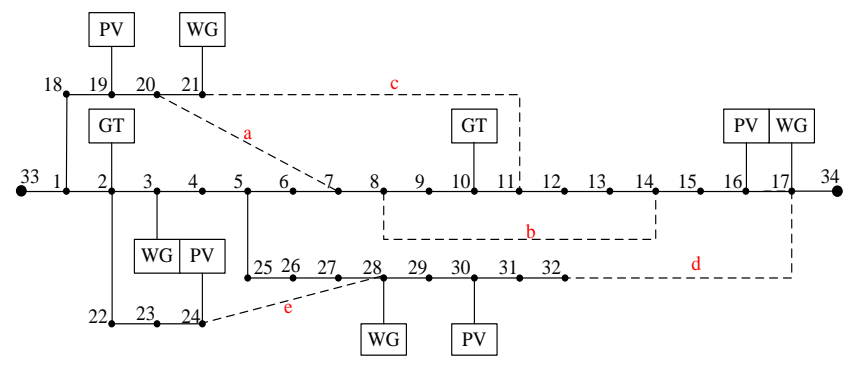

Fig. 4. 34-node system after modification.

To reflect operation features of $\mathrm{ADN}$ and achieve coordinated control between power supply sub regions, we add a substation node to IEEE33 nodes distribution network and change it to a 34-node distribution network, as in Fig. 4. 
The system includes 32 load nodes and 33 feeders. The nodes 33 and 34 are substation nodes. The maximum load of the whole system is $8.63 \mathrm{MW}$.

To strengthen the reliability of the system, one of the candidate planning feeders $(\mathrm{a}, \mathrm{b}, \mathrm{c}, \mathrm{d}, \mathrm{e})$ is selected to be newly constructed. Investment costs of feeders and DG are as in Table I, supposing that expansion fees of feeders are half of new construction fees. Candidate access nodes of DG and loads are as in Table II and Table III.

\begin{tabular}{|c|c|c|c|c|}
\hline \multicolumn{2}{|c|}{ Model } & Safety current (A) & $\begin{array}{l}\text { investment costs } \\
\text { (Y) }\end{array}$ & $\begin{array}{c}\text { Lifetime } \\
\text { (year) }\end{array}$ \\
\hline \multirow{5}{*}{$\begin{array}{c}\text { Wire } \\
\text { Cross } \\
\text { section } \\
\left(\mathrm{mm}^{2}\right)\end{array}$} & 95 & 200 & $195246 / \mathrm{km}$ & 15 \\
\hline & 120 & 225 & $249682 / \mathrm{km}$ & 15 \\
\hline & 150 & 265 & $290383 / \mathrm{km}$ & 15 \\
\hline & 185 & 295 & $350736 / \mathrm{km}$ & 15 \\
\hline & 240 & 345 & $454055 / \mathrm{km}$ & 15 \\
\hline \multicolumn{3}{|c|}{ Wind generator } & $5362 / \mathrm{kW}$ & 20 \\
\hline \multicolumn{3}{|c|}{ Photovoltaic generator } & $8600 / \mathrm{kW}$ & 25 \\
\hline \multicolumn{3}{|c|}{ Gas turbine } & $4950 / \mathrm{kW}$ & 20 \\
\hline
\end{tabular}

\begin{tabular}{ccc}
\multicolumn{4}{c}{ TABLE II: CANDIDATE ACCESS NODES OF DG } \\
\hline \hline Type of energy & $\begin{array}{c}\text { Single capacity } \\
\text { (MW) }\end{array}$ & $\begin{array}{c}\text { Candidate access } \\
\text { nodes }\end{array}$ \\
\hline Wind generator & 0.2 & $\{3,17,21.28\}$ \\
Photovoltaic generator & 0.1 & $\{16,19,24,30\}$ \\
Gas turbine & 0.3 & $\{1,3,15,17\}$ \\
\hline \hline
\end{tabular}

TABLE III: CANDIDATE ACCESS NODES OF NEW LOADS

\begin{tabular}{cccc}
\hline \hline Load node & $\begin{array}{c}\text { Active } \\
\text { power } \\
(\mathrm{kW})\end{array}$ & $\begin{array}{c}\text { Reactive } \\
\text { power }(\mathrm{kVar})\end{array}$ & $\begin{array}{c}\text { Candidate } \\
\text { access nodes }\end{array}$ \\
\hline 33 & 150 & 125 & $\{18,19,20,21\}$ \\
34 & 50 & 15 & $\{22,23,24,25\}$ \\
35 & 100 & 40 & $\{26,27,28,29\}$ \\
\hline \hline
\end{tabular}

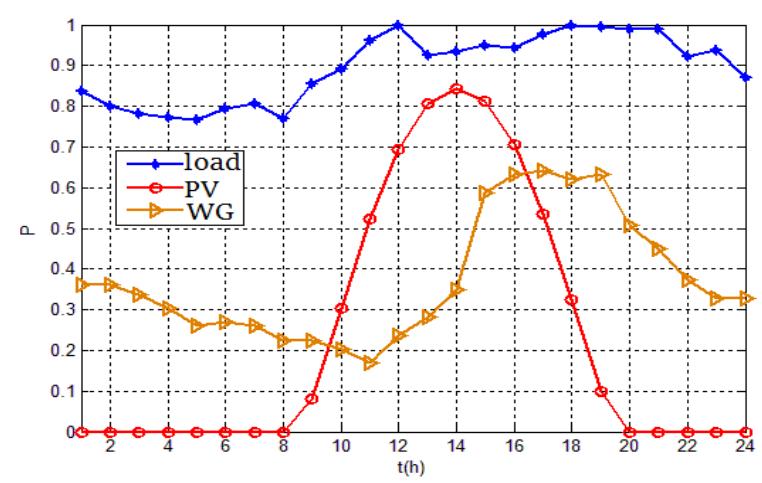

Fig. 5. The typical daily load curve and RDG output curve.

Typical daily load curve and typical output curve of RDG in this area are as in Fig. 5, and numerical values in the figure are transformed to per-unit values on the basis of respective maximum output. The peak-usual-valley periods acquired by semi-trapezoid membership function are as follows: the peak periods: seven hours including 11:00 12:00, 17:00 21:00; the usual periods: ten hours including 1:00, 9:00 10:00, 13:00 16:00, 22:00 24:00; the valley periods: seven hours including 2:00 8:00. Suppose that electricity price is 0.35 $¥ / \mathrm{kWh}$ purchased by distribution company from the superior grid, and the electricity sale price to users before DR is 0.56 $¥ / \mathrm{kWh}$. As for this system, five scenarios are made according to output deviation of RDG. The probability and related additional prices of all scenarios are as in Table IV.

Supposing 30\% of loads are non-postponed. And the users' satisfaction about electricity supply is required to be no less than 1. NSGA-II multi-objective optimization algorithm is adopted to gain planning results. After evolution of 100 generation of a population of 50 individuals, the results are as in Fig. 6.

TABLE IV: PROBABILITY AND ADDITIONAL ELECTRICITY PRICE OF EACH SCENARIO

\begin{tabular}{cccc}
\hline \hline Scene & $\begin{array}{c}\text { RDG output } \\
\text { deviation }\end{array}$ & Probability & $\begin{array}{c}\text { Additional electric } \\
\text { prices }(Y / \mathrm{kWh})\end{array}$ \\
\hline 1 & $u \geqslant 0.2$ & 0.1 & -0.25 \\
2 & $0.1 \leqslant u<0.2$ & 0.2 & -0.15 \\
3 & $-0.1 \leqslant u<0.1$ & 0.4 & 0 \\
4 & $-0.2 \leqslant u<-0.1$ & 0.2 & 0.15 \\
5 & $u \leqslant-0.2$ & 0.1 & 0.25 \\
\hline \hline
\end{tabular}

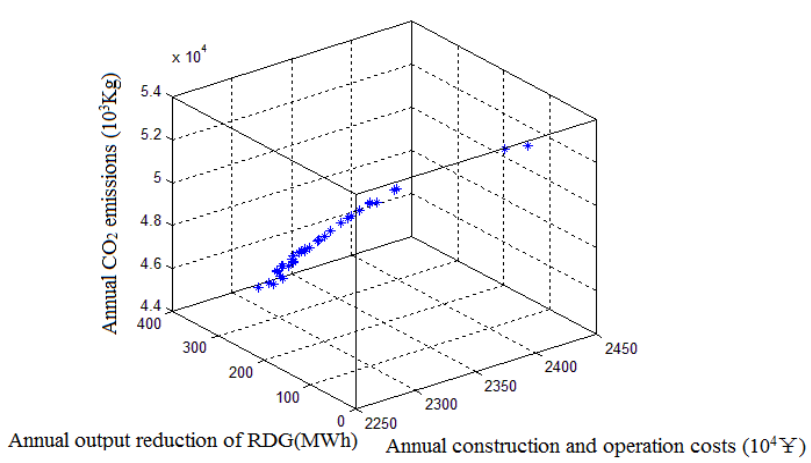

Fig. 6. Results of the distribution network planning.

Fig. 6 shows many non-dominated solutions of ADN planning, which are alternative planning schemes. The total capacity scale of RDG including wind generations and photovoltaic power stations is $1.4 \mathrm{MW}$ to $4.4 \mathrm{MW}$, annual construction cost scale is $¥ 1,794,900$ to $¥ 2,784,800$, annual operation cost scale is $¥ 20,252,800$ to $¥ 22,454,700$, total cost scale of annual construction and operation is from $¥ 22,760,000$ to $¥ 24,250,000$, and annual reduction of unit capacity RDG differs a lot, the scale of which is $83.17 \mathrm{MWh}$ to $320.18 \mathrm{MWh}$. Scale of annual emission volumes of carbon dioxide is 45,249 ton to 52,262 ton. Three cases are chose to be analyzed and compared, as in Table V.

TABLE V: Distribution NeTwork PlanNing RESUlts OF THREe CASES

\begin{tabular}{cccc} 
Schemes & Scheme & Scheme & Scheme \\
& A & B & C \\
\hline \hline Wind power capacity $(\mathrm{MW})$ & 3.2 & 2.4 & 1.6 \\
Photovoltaic capacity $(\mathrm{MW})$ & 1.2 & 1 & 0.7 \\
Gas turbine capacity $(\mathrm{MW})$ & 3 & 2.1 & 3 \\
Annual construction cost $\left(10^{4} ¥\right)$ & 263.6 & 202.8 & 181.2 \\
Annual operation cost $\left(10^{4} ¥\right)$ & 2028.1 & 2084.9 & 2173.4 \\
General cost for every year $\left(10^{4} ¥\right)$ & 2291.7 & 2287.7 & 2354.5 \\
Reduction of RDG output $(\mathrm{MWh})$ & 320.1 & 236.9 & 189.9 \\
Emission volumes of $\mathrm{CO}_{2}\left(10^{3} \mathrm{~kg}\right)$ & 45312 & 47655 & 50209 \\
Users' satisfaction & 1.035 & 1.019 & 1.020 \\
\hline \hline
\end{tabular}

Generally speaking, installation of RDG increases construction cost of system. But RDG has no fuel consumption and it decrease the electricity purchased by the distribution company from the superior grid, so operation cost is decreased. Use of RDG decreases greatly the emission 
volumes of $\mathrm{CO}_{2}$, which has strong benefits of environmental protection. Reserve gas turbines can decrease output reduction of RDG, but its high fuel fees may add up operation cost and the emission volumes of $\mathrm{CO}_{2}$ will increase. Users can select appropriate scheme according to important degrees of all indicators.

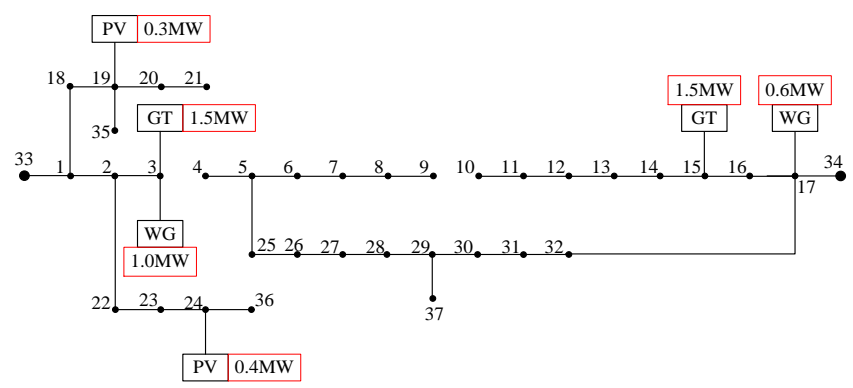

Fig. 7. Network operating structure of solution C.

To analyze the impact of electricity price strategy and demand response to ADN planning, taking scheme $\mathrm{C}$ for example, the operating structure of which is as in Fig. 7, planning results basing on different electricity price strategy are as in Table VI.

TABLE VI: RESULTS OF DIFFERENT ELECTRICITY PRICE STRATEGY

\begin{tabular}{ccccc}
\hline \hline Ways of electric prices & $\# 1$ & $\# 2$ & $\# 3$ & $\# 4$ \\
\hline $\begin{array}{c}\text { Time-of-use electric } \\
\text { prices }\end{array}$ & N/A & $\sqrt{ }$ & N/A & $\sqrt{ }$ \\
$\begin{array}{c}\text { Temporary additional } \\
\text { electric prices }\end{array}$ & N/A & N/A & $\sqrt{ }$ & $\sqrt{ }$ \\
\hline $\begin{array}{c}\text { Construction cost }\left(10^{4} Y\right) \\
\text { Operation cost }\left(10^{4} ¥\right)\end{array}$ & 181.8 & 181.2 & 181.8 & 181.2 \\
General cost $\left(10^{4} ¥\right)$ & 2412.9 & 2411.0 & 2383.8 & 2354.5 \\
Output reduction of RDG & 346.1 & 346.6 & 190.0 & 189.9 \\
$\quad$ MWh) & 50999 & 50976 & 50853 & 50209 \\
$\mathrm{CO}_{2}$ Emissions $\left(10^{3} \mathrm{~kg}\right)$ & 3.77 & 0.73 & 2.38 & 0 \\
Load shedding $(\mathrm{MWh})$ & & & & \\
\hline \hline
\end{tabular}

It is thus clear that demand response can influence distribution network planning and improve planning indicators. Implementation of TOU price decreases volumes of load shedding of distribution network, and strategy of temporary additional electric price may effectively decrease output reduction of RDG and encourage absorption of RDG. And because RDG has no fuel fees, correspondingly the operation cost is greatly decreased.

The measures of TOU and additional price make the planning indicators improve obviously. Total cost of construction operation for every year is decreased from $¥ 24,128,500$ to $¥ 23,545,300$, which decreases by $¥ 583,200)$; Output reduction of RDG for every year is decreased obviously from $346.08 \mathrm{MWh}$ to $189.81 \mathrm{MWh}$, which decreases by $156.27 \mathrm{MWh}$; Emission volumes of $\mathrm{CO}_{2}$ for every year are decreased from 50999.3 ton to 50209.0 ton, which decreases 790.3 ton); More importantly, phenomenon of load shedding is avoided completely and users' satisfaction about electricity supply is improved.

\section{CONCLUSION}

This paper put forward an ADN planning model considering of DR and uncertainty of RDG output. Impact of TOU price on load and additional price on utilization efficiency of RDG has been integrated to operation of distribution network. The results show that installation of RDG increases the construction cost of system and decreases operation cost; reserve gas turbines can effectively decrease reduction of RDG output. TOU price can be beneficial to lower overload level during peak-load periods and additional price may adjust load in real-time, encourage absorption of uncertain RDG, decrease its output reduction, improve usage efficiency and meanwhile further decrease operation cost of grid.

Optimization objectives of the model include construction and operation costs of distribution network company, utilization efficiency of RDG and emission reduction, meanwhile the constrains contain users' satisfaction about electricity supply, so the model considering both benefits of distribution company and users. NSGA-II multi-objective optimization algorithm adopted can handle objective function of different dimensions, different kinds and even contradictory. It put forward many reasonable schemes for choice which is suitable for solution of ADN planning.

\section{REFERENCES}

[1] W. Bao, X. H. Hu, G. Q. He, and G. H. Li, "Study on standard for grid-integration of distributed resources," Power System Technology, vol. 36, no. 11, pp. 46-52, 2012.

[2] Z. K. Wang, Y. X. Huang, and Y. Jun, “Application prospect and advantages of power supply system based on $20 \mathrm{kV}$ power distribution network and microgrid in China," Applied Mechanics and Materials, vol. 55-57, pp. 1357- 1360, 2011.

[3] D. Adamo, S. Jupe, and C. Abbey, "Global survey on planning and operation of active distribution networks - update of CIGRE C6.11 working group activities," presented at the 20th International Conference on Electricity Distribution (CIRED 2009), Prague, CZ, June 8-11, 2009

[4] N. Liu, L. Ma, and T. M. Zhu, "Synthetical assessment on distribution network planning scheme considering anti-disaster ability and regional characteristics," Power System Technology, vol. 36, no. 5, pp. 219-225, 2012.

[5] L. Cheng, G. Jiao, and H. Tian, "A method of distribution network planning with coordination of reliability and economics," Power System Technology, vol. 34, no. 11, pp. 106-110, 2010.

[6] J. Xiao, T. Zhang, Y. Zhang, and C. S. Wang, "TSC-based planning idea and method for distribution networks," Proceedings of the CSEE, vol. 33, no. 10, pp. 106-113, 2013.

[7] M. T. Fan and Z. P. Zhang, "Related issues of the active distribution network planning," Distribution \& Utilization, vol. 1, pp. 22-27, 2014

[8] M. T. Fan, H. Hui, and Z. P. Zhang, "Main impacts on active distribution system planning," Electric Power Construction, vol. 36, no. 1, pp. 60-64, 2015.

[9] J. H. Zhang, B. Zeng, Y. Y. Zhang, D. C. Liu, X. Yang, and C. Li, "Key issues and research prospects of active distribution network planning," Transactions of China Electro Technical Society, vol. 29, no. 2, pp. $13-23,2014$

[10] S. Wong, K. Bhattacharya, and J. D. Fuller, "Electric power distribution system design and planning in a deregulated environment," IET Generation, Transmission \& Distribution, vol. 3, pp. 1061-1078, Dec. 2009.

[11] T. Lv, W. Tang, P. W. Cong, and B. Bo, "Multi-objective coordinated planning of distribution network incorporating distributed generators," Automation of Electric Power Systems, vol. 37, no. 21, pp. 139-145, 2013.

[12] C. L. T. Borges and V. F. Martins, "Multistage expansion planning for active distribution networks under demand and distributed generation uncertainties," International Journal of Electrical Power \& Energy Systems, vol. 36, no. 1, pp. 107-116, 2012.

[13] K. Deb, S. Agrawal, and A. Pratap, "A fast elitist non-dominated sorting genetic algorithm for multi-objective optimization: NSGA-II," Lecture Notes in Computer Science, vol. 1917, pp. 849-858, 2000. 
[14] S. Y. Ge, J. W. Guo, H. Liu, and P. L. Zeng, "Impacts of electric vehicle's ordered charging on power grid load curve considering demand side response and output of regional wind farm and photovoltaic generation," Power System Technology, vol. 38, no. 7, pp. 1806-1811, 2014.

[15] D. R. Wang, "Application of price-based demand side response in the USA," Power DSM, vol. 12, no. 4, pp. 74-77, 2010.

[16] K. Dietrich, J. M. Latorre, and L. Olmos, "Demand response in an isolated system with high wind intergration," IEEE Trans. on Power Systems, vol. 27, no. 1, pp. 20-29, 2012.

[17] K. Sun, "Environmental cost analysis and research of different power plants," Energy Engineering, vol. 3, pp. 23-26, 2004.

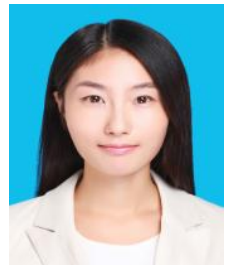

Nan Li was born on May 12, 1986 in Suqian city, Jiangsu province, China and earned the Ph.D. degree of engineering in June, 2015 from China Electric Power Research Institute, Beijing, China.

She has worked in the State Grid Energy Research Institute, Beijing, China. She is mainly engaged in energy planning for power generations. 